\title{
Myositis-specific autoantibodies: detection and clinical associations
}

\author{
Sander H. J. van Dooren - Walther J. van Venrooij • \\ Ger J. M. Pruijn
}

Received: 22 December 2010/ Accepted: 11 January 2011/Published online: 23 March 2011

(C) Springer-Verlag 2011

\begin{abstract}
In recent years, the detection and characterization of (novel) autoantibodies is becoming increasingly important for the early diagnosis of autoimmune diseases. The idiopathic inflammatory myopathies (IIM, also indicated with myositis) are a group of systemic autoimmune disorders that involve inflammation and weakness of skeletal muscles. One of the hallmarks is the infiltration of inflammatory cells in muscle tissues. A number of myositis-specific autoantibodies have been identified and these may be associated with distinct IIM subclasses and clinical symptoms. Here, we review all myositis-specific autoantibodies identified today as well as their target proteins, together with their clinical associations in IIM patients. Post-translational modifications that might be associated with the generation of autoantibodies and the development of the disease are discussed as well. In addition, we describe well established autoantibody detection techniques that are currently being used in diagnostic laboratories, as well as novel multiplexed methods. The latter techniques provide great opportunities for the simultaneous detection of distinct autoantibodies, but may also contribute to the identification of novel autoantibody profiles, which may have additional diagnostic and prognostic value. The ongoing characterization of novel autoantibody specificities emphasizes the complexity of processes involved in the development of such autoimmune diseases.
\end{abstract}

S. H. J. van Dooren · W. J. van Venrooij · G. J. M. Pruijn ( $\square)$

271 Department of Biomolecular Chemistry,

Nijmegen Centre for Molecular Life Sciences,

Institute for Molecules and Materials,

Radboud University Nijmegen, PO Box 9101,

6500 HB Nijmegen, The Netherlands

e-mail: G.Pruijn@ncmls.ru.nl
Keywords IIM - Myositis-specific autoantibodies · Autoantibody detection - Autoantigen - Multiplex assays . Post-translational modification

\section{Autoantibodies in idiopathic inflammatory myopathies}

Autoantibodies directed against a variety of autoantigens are strongly associated with systemic autoimmune diseases. Within the heterogeneous group of connective tissue diseases (CTD), a wide range of nuclear and cytoplasmic autoantigenic targets have been described. However, it is still unclear why autoantibodies directed against these autoantigens are formed and whether they participate in pathological processes during disease development and/or progression. Post-translational modifications (PTMs) have been hypothesized to generate novel epitopes in antigenic proteins. The cross-presentation of these post-translationally modified epitopes might break immunological tolerance and initiate the development of an autoimmune response resulting in autoantibody formation.

The idiopathic inflammatory myopathies (IIM) are a group of disorders characterized by inflammation and weakness mainly of the muscles closest to the trunk of the body (proximal muscles). These disorders include polymyositis (PM), dermatomyositis (DM) and inclusion body myositis (IBM). IIM may be associated with inflammation in other organs, including the joints, heart, lungs, intestines and skin. In IIM, like in other systemic autoimmune diseases, distinct clinical phenotypes can be correlated with specific autoantibody targets in patients, which emphasizes the clinical relevance of these biomarkers [1]. Autoantibodies found in IIM patients can be divided into myositisassociated autoantibodies (MAA), which are not specific for the disease and are also found in other rheumatic 
disorders, and myositis-specific autoantibodies (MSA), which are found primarily in patients with IIM. Tables 1 and 2 show a comprehensive overview of the autoantigens recognized by MSA and MAA together with their function. In this review, we will describe the most prevalent MSA in more detail, their detection and the clinical manifestations associated with them.

\section{Autoantibody detection assays}

The development of less invasive and more advanced imaging tools in order to discriminate between the clinical characteristics of various inflammatory myopathy subtypes, contributed greatly to the often difficult diagnosis of these diseases. The application of advanced techniques such as magnetic resonance imaging (MRI), X-ray computed tomography (CT), positron emission tomography (PET), and ultrasonography can also increase the sensitivity of detecting IIM prior to muscle biopsy [2]. In addition, several serological markers in IIM, which can be specific for certain IIM subtypes or be helpful in evaluating disease progression have been detected in the last decades. These biomarkers mostly are autoantibodies directed to one or more cellular components. The fact that only a limited number of proteins appear to be targets of autoantibodies suggests that distinct processes are involved in their generation.

A variety of techniques are available to detect the various autoantibodies for research or routine diagnostics, all with their distinct sensitivity and specificity traits. Conventional methods such as indirect immunofluorescence, immunoprecipitation, immunodiffusion and counterimmuno-electrophoresis, or immunoassays such as the enzyme-linked immunosorbent assay (ELISA) and
Table 1 Myositis-specific autoantibodies and their functional activities

\begin{tabular}{|c|c|c|c|}
\hline Autoantibody & Autoantigen & $\begin{array}{l}\text { Molecular } \\
\text { mass }(\mathrm{kDa})\end{array}$ & Function of autoantigen \\
\hline \multicolumn{4}{|l|}{ Anti-aaRS } \\
\hline Anti-Jo-1/PL1 & HisRS & 54 & \multirow[t]{8}{*}{ Aminoacylation of tRNAs } \\
\hline Anti-PL7 & ThrRS & 80 & \\
\hline Anti-PL12 & AlaRS & 106 & \\
\hline Anti-EJ & GlyRS & 75 & \\
\hline Anti-OJ & IleRS & 150 & \\
\hline Anti-KS & AsnRS & 65 & \\
\hline Anti-Ha & TyrRS & 58 & \\
\hline Anti-Zo & PheRS & $57 / 66$ & \\
\hline \multicolumn{4}{|l|}{ Anti-tRNA } \\
\hline & tRNA $^{\text {His }}$ & & \multirow[t]{2}{*}{ Translation } \\
\hline & $\mathrm{tRNA}^{\mathrm{Ala}}$ & & \\
\hline \multicolumn{4}{|l|}{ Anti-Mi-2 } \\
\hline & $\operatorname{Mi}-2 \alpha$ & 220 & \multirow[t]{2}{*}{$\begin{array}{l}\text { Transcription regulation } \\
\quad+\text { Nucleosome remodeling }\end{array}$} \\
\hline & $\mathrm{Mi}-2 \beta$ & 218 & \\
\hline \multicolumn{4}{|l|}{ Anti-SRP } \\
\hline & SRP54 & 54 & \multirow[t]{3}{*}{ Protein translocation to the ER } \\
\hline & SRP68 & 68 & \\
\hline & SRP72 & 72 & \\
\hline \multicolumn{4}{|l|}{ Anti-p155/140 } \\
\hline & Tif $1-\gamma$ & 155 & Ubiquitination \\
\hline & Unknown & 140 & n.d. \\
\hline \multicolumn{4}{|l|}{ Anti-CADM-140 } \\
\hline & MDA5 & 117 & Innate immunity (RNA sensor) \\
\hline \multicolumn{4}{|l|}{ Anti-SAE } \\
\hline & SAE1 & 38 & Sumoylation \\
\hline & SAE2 & 72 & \\
\hline \multicolumn{4}{|l|}{ Anti-p140 } \\
\hline & NXP-2 & 107 & RNA binding + nuclear transcription \\
\hline
\end{tabular}


Table 2 Myositis-associated autoantibodies and their functional activities
$P M / S c l$ polymyositis, scleroderma overlap, $R N P$ ribonucleoprotein, $P M S$ postmeiotic segregation, $e E F 1$ eukaryotic elongation factor 1 , n.d. not determined

\begin{tabular}{|c|c|c|c|}
\hline Autoantibody & Autoantigen & $\begin{array}{l}\text { Molecular } \\
\text { mass }(\mathrm{kDa})\end{array}$ & Function of autoantigen \\
\hline \multicolumn{4}{|l|}{ Anti-PM/Scl } \\
\hline & $\mathrm{PM} / \mathrm{Scl}-75$ & 75 & RNA processing + degradation \\
\hline & PM/Scl-100 & 100 & \\
\hline \multicolumn{4}{|l|}{ Anti-Mas } \\
\hline & $\begin{array}{l}\text { Serine-tRNA }{ }^{\text {Sec }} \text {-protein } \\
\text { complex }\end{array}$ & 48 & Selenocysteine incorporation \\
\hline \multicolumn{4}{|l|}{ Anti-Ro/SS-A } \\
\hline Anti-Ro52 & Ro52 & 52 & \\
\hline Anti-SS-A & Ro60 & 60 & RNA quality control \\
\hline \multicolumn{4}{|l|}{ Anti-La/SS-B } \\
\hline Anti-SS-B & $\mathrm{La}$ & 48 & $\begin{array}{l}\text { RNA binding }+ \text { Pol III } \\
\text { transcription }\end{array}$ \\
\hline \multicolumn{4}{|l|}{ Anti-RNP } \\
\hline & U1A & 34 & Pre-mRNA splicing \\
\hline & $\mathrm{U} 1 \mathrm{C}$ & 22 & \\
\hline & U1-70k & 70 & \\
\hline Anti-Wa & Peptide & 48 & Unknown \\
\hline Anti-PMS & a.o. PMS1, PMS2 & n.d. & $\begin{array}{l}\text { DNA binding protein complex } \\
\text { involved in DNA-repair }\end{array}$ \\
\hline \multicolumn{4}{|l|}{ Anti-Ku } \\
\hline & $\mathrm{Ku} 70$ & 70 & $\begin{array}{l}\text { DNA dependent } \\
\text { protein phosphorylation }\end{array}$ \\
\hline & $\mathrm{Ku} 80$ & 80 & \\
\hline \multicolumn{4}{|l|}{ Anti-Fer } \\
\hline & eEF1 & & Translation \\
\hline Anti-KJ & Peptide & $30 / 34$ & Translocation factor \\
\hline Anti-56K & Nuclear RNP & 56 & Unknown \\
\hline
\end{tabular}

immunoblotting are already in use for many years. In most cases, these techniques are suitable for the detection of a single autoantibody specificity. In contrast, a new generation of assays (so-called multiplexed analysis techniques) allows the simultaneous detection of several autoantibody specificities [3, 4]. The latter techniques probably will dominate serological profiling in diagnostic laboratories in the future provided that validation and reproducibility are ensured.

\section{Immunofluorescence}

Several antinuclear antibodies (ANA) are still being detected by indirect immunofluorescence on HEp-2 cells or tissue substrates. Some ANA-positive IIM sera may show a particular staining pattern that can be correlated with a distinct autoantigen. However, this technique is laborious and needs specific technical skills to perform. It is therefore less convenient for present day diagnostic analyses.
Immunoprecipitation, ELISA and immunoblotting

The most unambiguous way to determine the presence of autoantibodies against a particular autoantigen is the detection of an autoantibody by virtue of its binding to the antigen in its fully native state. Although the immunoprecipitation (IP) method is the most obvious choice, this technique is not widely applied because it is laborious, expensive and requires specific technical skills. Radiolabelled cell extracts are often used as substrates for immunoprecipitation assays and subsequent mass-spectrometry analysis can characterize the specific targets [5, 6] (Fig. 1). However, the antigen to be detected may be associated with other (non-antigenic) proteins and as a consequence the IP procedure often leads to a complex pattern of precipitated proteins of which only one or a few proteins are truly autoantigenic. Nevertheless, detection of autoantigenic biomarkers in IIM by immunoprecipitation techniques is still widely used. 


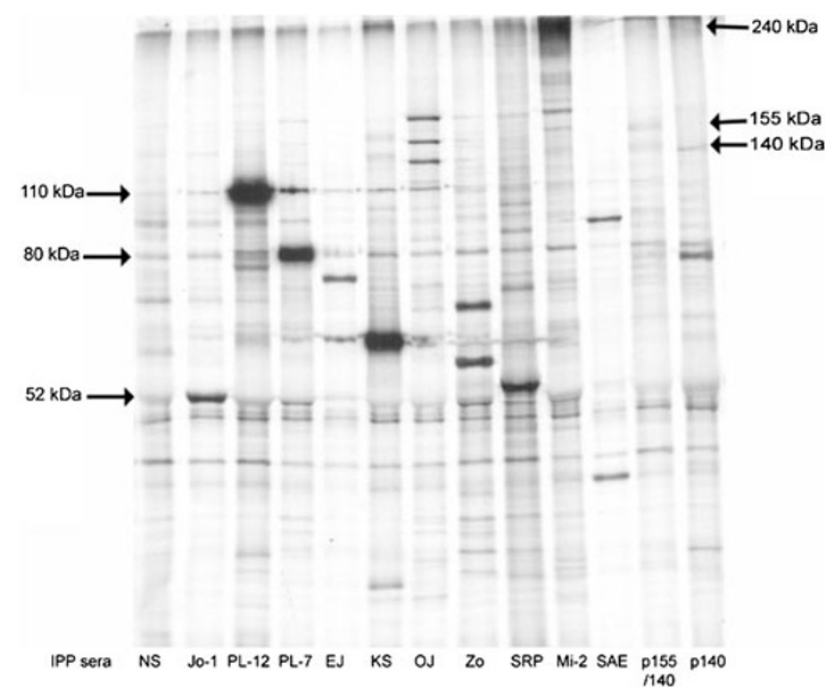

Fig. 1 Immunoprecipitation assay with myositis-specific autoantibodies. Polypeptides immunoprecipitated from ${ }^{35} \mathrm{~S}$-methioninelabelled K562 cell extracts by antibodies from patient sera were separated by SDS-polyacrylamide gelelectrophoresis and visualized by autoradiography. Sera used for immunoprecipitation included serum from a healthy individual (NS), anti-Jo-1, anti-PL-12, anti-PL-7, anti-EJ, anti-KS, anti-OJ, anti-Zo, anti-SRP, anti-Mi-2, anti-SAE, antip155/140, anti-p140 (reproduced from [6], by permission of The British Society for Rheumatology)

The first high-throughput assays such as ELISA increased the number of patient sera that could be analysed compared to the previously mentioned conventional assays. However, purification of the antigen and use of the correct reagents has to be monitored to warrant an optimal specificity [7, 8]. In addition, at least some conformational epitopes might be lost, because the antigen is bound to the ELISA plate. Immunoblotting (IB) analysis, in addition to ELISA, may increase the specificity of the signal detected in the immune assays. However, IB may allow the detection of autoantibodies only to linear epitopes, because the antigen is completely denatured during preparation of the blot. This might decrease sensitivity of the IB method as compared to IP and ELISA. As a consequence only, the ELISA method is widely used in routine laboratories where large numbers of sera have to be tested.

\section{Multiplex assays}

A number of multiplex-based assays have been developed during the years, with distinct methodological differences. In this review we will discuss the high-throughput-based micro-array format, described in this paragraph, and a macroscopic assay that has been developed for the simultaneous detection of multiple autoantibodies in IIM sera, the line-blot, which is described separately in the next paragraph. Multiplex assays are able to screen a single sample of blood or other biological fluid for an array of autoantibody specificities simultaneously. In this way a patient-specific autoantibody profile can be made. Future prospects suggest that antigen/patient-specific therapies might be developed from these patient-specific autoantibody profiles, which might prevent disease progression, remission or relapse over time. The basic principles of two main types of micro-array-based multiplex assays will be discussed below.

Solid surface-based autoantigen microarrays contain immobilized proteins or other biomolecules in predetermined positions on a solid surface. Interactions between the immobilized antigens and molecules in the serum sample such as (labelled) antibodies can be detected by fluorescence-based procedures $[4,9]$. Such antigen arrays have already been used to screen the autoantibody profiles in autoimmune diseases, IgE reactivity in allergy, and the immune response to infections, vaccination, and cancer reviewed by [4]. However, this technique is based on commercialized or home-made microarrays that depend on specific technical expertise and equipment (Fig. 2). In order to simplify technical aspects as much as possible socalled addressable-bead autoantigen microarrays have been developed [10, 11]. Individual antigens of interest are chemically coupled to beads of different colours. Subsequently, sera or other biological fluids can be analysed in a microtiter well containing a bead mixture as described by Tozzoli [3], Fritzler 12]. One laser will measure the colour of the specific antigen-coupled bead, whereas a second laser determines the presence and quantity of a fluorochrome-coupled secondary antibody bound to the bead (Fig. 3). Both autoantigen microarray techniques have advantages over the conventional techniques in terms of reduced sample volumes, enhanced sensitivity, automation and increased numbers of samples that can be tested. The

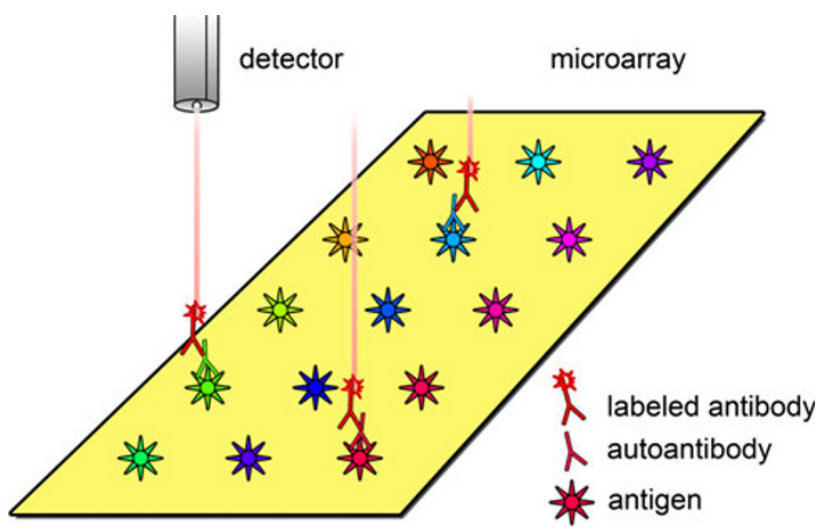

Fig. 2 Schematic representation of the solid surface-based autoantigen array. Autoantigenic molecules are immobilized at defined positions on a solid surface. Binding of autoantibodies in patient sera to the immobilized autoantigens can be detected via fluorescently labelled secondary antibodies 


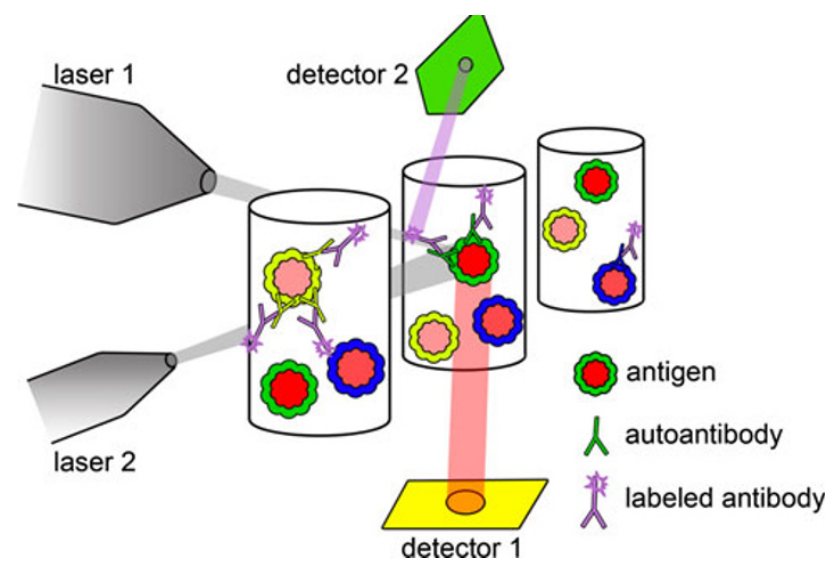

Fig. 3 Schematic representation of a addressable-bead autoantigen immunoassay. Purified autoantigens are coupled to differentially labelled microbeads that can be detected by illumination with a laser. Patient sera can be incubated with mixtures of beads each coated with a different autoantigen. One laser is used to identify the specific antigen coupled to each bead based upon the fluorescent properties of the bead, and a second laser is used to determine the binding of autoantibodies to the beads after incubation with secondary antibodies conjugated to a distinct fluorophore

sometimes imperfect specificity and reproducibility of these methods can be obstacles for their implementation in routine diagnostics.

Line-blot assay

The line-blot assays, or so-called line immunoassays (LIAs), are based on immunoblotting procedures that spot purified antigens on protein-binding membranes without the need of gel electrophoresis (Fig. 4). The laborious purification procedure of native antigens is being replaced by the more reproducible production of highly purified recombinant antigens or synthetic peptides. These developments contribute to the increased sensitivity and specificity of commercially available line-blots. Several LIAs of different manufacturers have recently been clinically validated in multicenter studies, and the results indicate that LIAs are becoming a suitable alternative to the more costly and complex techniques sometimes used in diagnostic laboratories reviewed by [13, 14].

\section{Myositis-specific autoantibodies}

Aminoacyl-tRNA synthetases

\section{Function}

An efficient and reliable transcription and translation of the genetic code is essential for cell survival. Genes are transcribed into messenger RNA (mRNA), which contains a

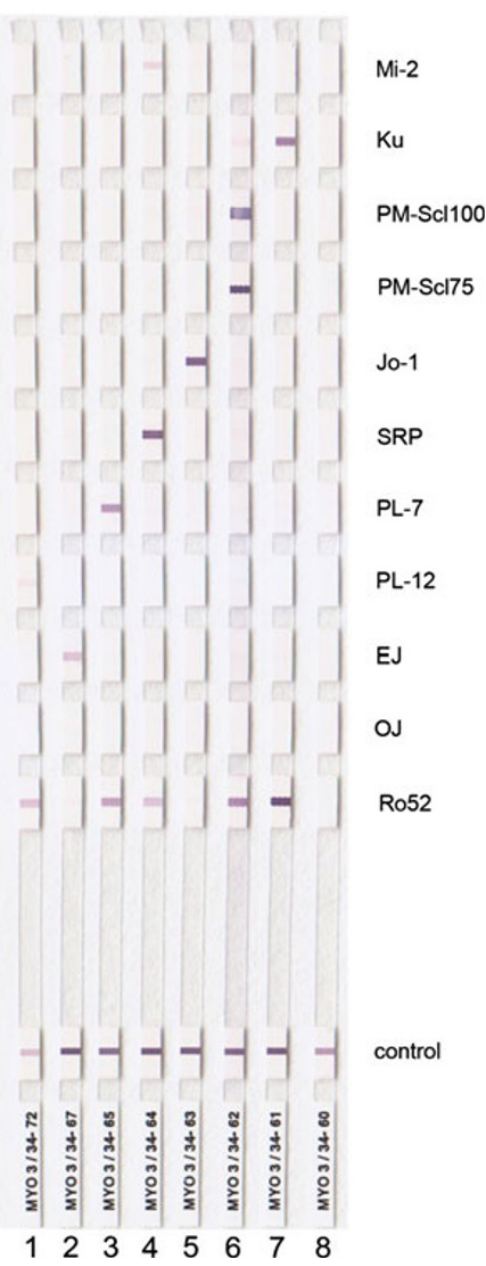

Fig. 4 Line-blot for autoantibody detection in IIM sera. Strips (vertical) containing a series of recombinant IIM-related autoantigens were incubated with seven IIM patient sera (1-7) and a control serum (8). Antibody binding was visualized using the protocol provided by the manufacturer. The strips were incubated with sera containing the following autoantibodies (1) anti-PL12, (2) anti-EJ, (3) anti-PL7, (4) anti-SRP and anti-Mi-2, (5) anti-Jo-1, (6) anti-PM-Scl75 and antiPM-Scl100, (7) anti-Ku

string of nucleotide triplets, called codons. During translation every codon is translated into one particular amino acid (aa) with the help of transfer RNAs (tRNAs) (Fig. 5). The mRNA sequence is thus converted into a chain of amino acids that makes up a functional polypeptide. The tRNAs involved are specific for both the amino acid and the mRNA codon. The amino acids are coupled to their cognate tRNA via an esterification reaction that is catalyzed by specific aminoacyl tRNA synthetases (aaRSs) in a two-step reaction:

$$
\begin{aligned}
& \text { aaRS }+ \text { aa }+ \text { ATP aaRS } \leftrightarrow \text { aa } \sim \text { AMP }+\mathrm{PPi} \\
& \text { aaRS } * \text { aa } \sim \text { AMP }+ \text { tRNA } \leftrightarrow \text { aaRS }+ \text { aa-tRNA }+ \text { AMP }
\end{aligned}
$$

Most of the 20 canonical amino acids are recognized by a single aaRS, with the exception of GluRS and ProRS in 


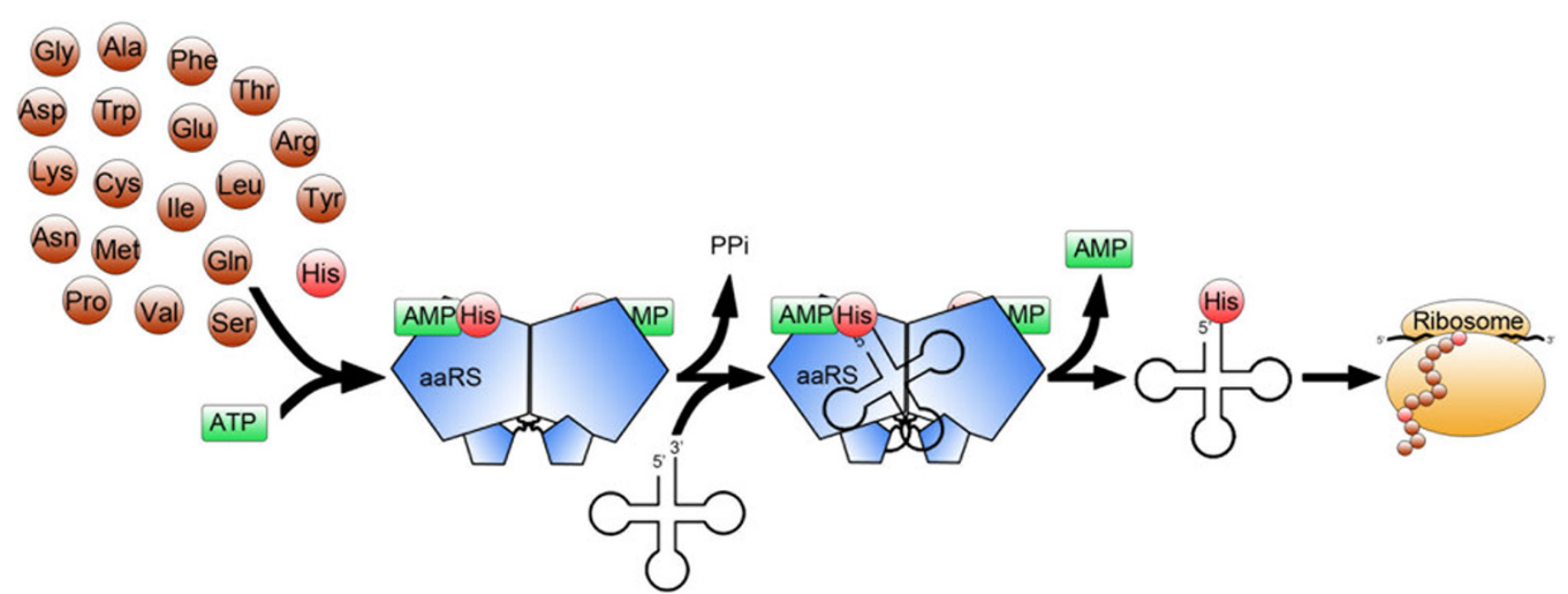

Fig. 5 Aminoacylation of tRNA by histidyl-tRNA synthetase. The HisRS, as well as other aaRSs, catalyze the ATP-dependent esterification reaction that is needed to couple an amino acid to its

higher eukaryotes $[15,16]$. The aminoacylated-tRNA, or so-called charged tRNA, is used by the ribosome to incorporate the appropriate amino acid into the growing peptide chain.

In addition to the wellknown function of aaRSs described above, a diverse array of other biological functions has been described as well. These include amino acid biosynthesis, DNA replication, RNA splicing, cell cycle control, and apoptosis (reviewed by $[17,18]$ ).

Depending on highly conserved sequence motifs and aminoacylation acitivities, the aaRSs can be divided into two classes, Class I and Class II, and three sub-classes a, b, and c (Fig. 6). The catalytic domain of Class I aaRSs consists of a typical Rossmann fold (nucleotide-binding domain) and two highly conserved sequence motifs whereas the Class II aaRSs are characterized by an antiparallel $\beta$-strand surrounded by $\alpha$-helices, and three conserved sequence motifs [19]. Additionally, Class I aaRSs mainly exist as monomeric or dimeric complexes and aminoacylate the $2^{\prime}$-hydroxyl group of the terminal ribose of tRNA. Class II aaRSs usually are dimeric or tetrameric structures and aminoacylate the $3^{\prime}$-hydroxyl group of the terminal ribose. The only exception is the PheRS that belongs to the Class II aaRSs but nevertheless aminoacylates the $2^{\prime}-\mathrm{OH}$ of the ribose. Higher eukaryotic cells have been shown to contain a high molecular mass multi-synthetase complex (MSC), which contains nine aaRSs and three accessory proteins (Fig. 6). The MSC is thought to promote protein synthesis, proofreading activity, and serve as a reservoir of regulatory molecules that are involved in functions other than aminoacylation [20, 21]. cognate tRNA. Subsequently, the aminoacylated-tRNA can be used in translation. AMP adenosine monophosphate, ATP adenosine triphosphate, $P P i$ inorganic phosphate

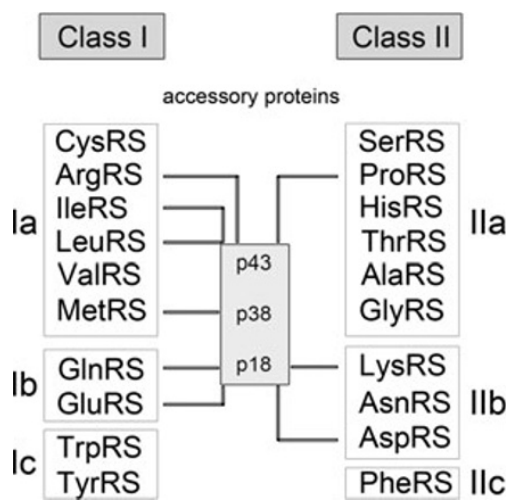

Fig. 6 Classification of aminoacyl-tRNA synthetases. AaRSs are (sub)classified according to the chemical specificity of the reaction they catalyze and on the presence of conserved domains in their amino acid sequences (Class I and II, and subclasses a, b, and c). The aaRS that are associated with the multisynthetase complex (MSC) are connected to the three MSC accessory proteins (p43, p38, and p18) via bold lines

\section{Potentially disease-related PTMs}

Three aaRSs (HisRS, AlaRS, and IleRS) have been described as substrates for the serine protease Granzyme B (GrB), which is present in granules of cytotoxic T lymphocytes (CTLs) or natural killer (NK) cells and plays an important role in granule exocytosis-induced cytotoxicity $[22,23]$. The exposure to GrB leads to unique fragments of autoantigens, which are not detected during other forms of cell death [24]. Indeed, almost all IIM autoantigens (except $\mathrm{SSA} / \mathrm{Ro52}$ ) can be cleaved by $\mathrm{GrB}$, in contrast to nonautoantigenic proteins, which are either not cleaved or cleaved at sites also used by caspases [24]. The fragments 
generated by $\mathrm{GrB}$, which are believed to contain new and unique epitopes, may help in breaking tolerance against the autoantigens when they are encountered by the immune system. The cleavage products as well as the full-length autoantigenic HisRS and AsnRS have been described to exert chemotactic properties through their interaction with the chemokine receptors CCR3 or CCR5, in contrast to the non-autoantigenic AspRS and LysRS [25, 26]. Levine et al. [27] found a proteolytically sensitive HisRS conformation in normal lungs compared to muscle tissue and proposed the lung as a target site where initiation and propagation against HisRS may take place. However, the GrB-induced aaRS fragmentation and the subsequent dendritic cell-driven autoreactive $\mathrm{CD}^{+}{ }^{+} \mathrm{T}$ cell activation have not been demonstrated in IIM patients yet.

An additional cleavage product of HisRS has been described by Ramirez-Sandoval et al. [28] upon the induction of apoptosis in HEp-2 cells by camptothecin. Also TyrRS, and its close homologue TrpRS, are both described to stimulate chemotactic activities as well as angiogenesis in vitro upon cleavage [29, 30]. The exposure to reactive oxygen and/or nitrogen species (ROS/RNS) may also lead to post-translationally modified biomolecules and result in the loss of immunological tolerance. Interestingly, increased levels of ROS/RNS have been reported to be present in inflammatory autoimmune diseases [31, 32]. We have observed selective oxidative modifications in HisRS, but the significance of these for IIM remains to be established (Van Dooren et al., manuscript submitted for publication)

\section{Antibodies to aaRSs and their clinical associations}

Autoantibodies directed to aminoacyl-tRNA synthetases are the most commonly detected MSA in adult IIM patients. They can be found in about $40 \%$ of individuals with IIM and in lower frequencies in juvenile IIM patients [33]. In addition, autoantibodies against the cognate tRNAs have been found [34, 35]. Most anti-aminoacyl-tRNA synthetase antibodies (anti-aaRS) are directed against the Class II aaRSs, including PL1/Jo-1 (HisRS), PL7 (ThrRS), PL12 (AlaRS), EJ (GlyRS), KS (AsnRS), and Zo (PheRS). Only two Class I aaRS autoantibody targets, namely OJ (IleRS) and Ha (TyrRS) have been described so far [6]. Most IIM patients with anti-aaRS produce autoantibodies against a single aaRS, although in rare cases antibodies may occur directed to two aaRSs [36].

The anti-Jo-1 (or anti-HisRS) is the most frequently occurring autoantibody in PM/DM patients, its presence nearly excludes one of the three IIM, being inclusion-body myositis [37-39]. Different clinical and immunological features are associated with the presence of anti-Jo-1 antibodies, but whether the autoantibodies are a cause or a consequence of the development of the disease remains unknown, despite the fact that a correlation between the titer of anti-Jo-1 antibody and disease activity has been observed [40].

The major epitope of the Jo-1 molecule has been defined as a coiled-coil structure within the protein [41], although antibodies directed to other parts of the Jo- 1 protein can be detected as well [42, 43]. Class switching, affinity maturation, species-specificity, and spectrotype broadening during the Jo-1 antibody response have been detected, which suggests a $\mathrm{T}$ cell-dependent and antigen-driven response in IIM patients [41, 43-45]. These processes also suggest that epitope spreading during the course of the disease may occur. Most studies that investigate the autoepitopes on the Jo-1 protein report activities that recognize multiple, both linear and conformation-dependent Jo-1 epitopes.

Myositis-specific autoantibody profiles are often associated with distinct clinical features [46]. Indeed, anti-aaRS antibodies are associated with a unique clinical syndrome, the so-called anti-synthetase syndrome. Characteristics of the anti-synthetase syndrome include myositis, Raynaud's phenomenon, arthralgia, fever, skin changes and interstitial lung disease, although clinical features may differ between patients with the anti-synthetase syndrome [47, 48]. The interstitial lung disease is important as it may negatively affect prognosis [49].

A number of studies investigated the genetic background of IIM patients and tried to correlate phenotypic characteristics with genetic predispositions. Besides associations with the human leukocyte antigen (HLA) 8.1 ancestral haplotype (HLA-DRB1*03-DQA1*05DQB1*02), significant correlations were found between the presence of anti-Jo-1 antibody and HLA-DRB1*0301 and/or HLA-DPB $1 * 0101$ (reviewed by [50]). There are also data supporting the idea that candidate IIM autoantigens can be involved in the induction and propagation of the autoimmune response. The expression of the Jo-1 antigen was found to be elevated in regenerating muscle of IIM patients compared to normal muscle [51, 52]. However, clear pathologic relevance of these antibodies in IIM has not been found yet.

\section{How to assay for anti-aaRS antibodies}

Commercially based LIAs can be used to test for several anti-aaRS antibodies, including anti-Jo-1, anti-PL7, and anti-PL12 (see Fig. 4; [13, 14, 53]). However, reaction conditions (e.g. temperature) have to be standardized, because they can have profound effects on the experimental outcome [13]. Recently, LIA strips have been developed that also detect anti-EJ and anti-OJ reactivities. Other less frequently found anti-aaRS reactivities such as 
anti-KS, anti-Ha, and anti-Zo are not commercially exploited yet. The latter anti-aaRSs are still being detected by the more conventional immunoblot- and immunoprecipitation-based techniques.

\section{Mi-2}

\section{Function}

The chromatin in the nucleus of eukaryotic cells consists of a densely packed complex of DNA and proteins. The basic structure is the nucleosome, each of which contains an octamer of four core histones ( $\mathrm{H} 2 \mathrm{~A}, \mathrm{H} 2 \mathrm{~B}, \mathrm{H} 3$, and $\mathrm{H} 4)$ and a piece of approximately 150 basepairs DNA tightly wrapped around it. To allow gene transcription and chromosome replication, the chromatin is dynamically and orderly unfolded and, after replication or transcription repression, reformed.

Chromatin structure remodeling is mainly regulated via two mechanisms reviewed by $[54,55]$. The first involves covalent modification of nucleosomes such as methylation of DNA and (de-)acetylation of lysine residues in the core histones. The second mechanism involves dynamic changes of the histone-DNA interactions within the nucleosome in an ATP-dependent manner, which results in an increased or decreased accessibility of nucleosomal DNA (Fig. 7). The major remodeling enzymes involved can be categorized based on their ATPase subunits. These include the ISWI/SNF2L-type ATPases and the chromodomain helicase DNA-binding (CHD) protein family.

The Mi-2 protein was first identified as a DM-specific autoantigen and later shown to be a subunit of the nucleosome remodeling and deacetylation (NuRD) complex [56, 57]. The core subunits of the Mi-2/NuRD complexes are

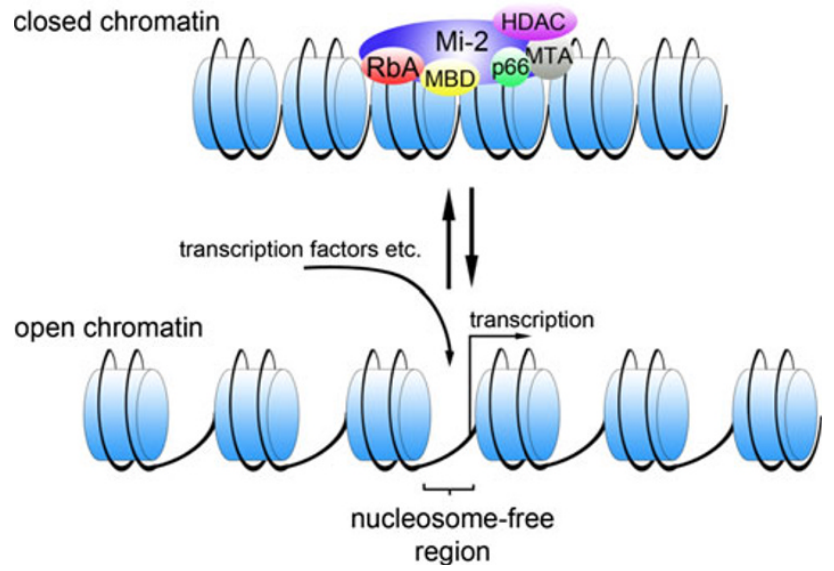

Fig. 7 Predicted model of chromatin remodeling by the Mi-2/NuRD complex. The core subunits of the Mi-2/NuRD complex are suggested to be involved in modifying the chromatin structure, which can result in the initiation and/or maintenance of gene repression classified into the CHD protein family and are found to occur in different subunit compositions, depending on their functional activity reviewed by [58]). The components include histone de-acetylases (HDAC1 and HDAC2), retinoblastoma associated proteins (RbAp), metastasis-associated protein (MTA), a methyl-CpG-binding domain containing protein (MBD), and either one of the highly related $\mathrm{Mi}-2 \alpha$ (CHD3) and $\mathrm{Mi}-2 \beta$ (CHD4) proteins [58-60]. The NuRD complexes are unique transcriptional regulators since they combine three enzymatic activities, namely histone deacetylation, histone demethylation, and ATP-dependent chromatin remodeling activities.

\section{Potentially disease-related PTMs}

The Mi-2/NuRD complex or Mi-2 protein complex has been described to be a substrate for modifying enzymes such as enzymes conjugating the small ubiquitin-related modifier (SUMO) and GrB [24, 61]. However, a direct relation between modified protein and IIM pathogenesis has not been demonstrated yet.

\section{Antibodies to Mi-2 and their clinical associations}

Reichlin and co-workers were the first to describe anti-Mi-2 antibodies in IIM patients and to date the anti-Mi-2 antibody can be detected in up to $20 \%$ of DM patients $[62,63]$. The anti-Mi-2-positive patient sera are able to immunoprecipitate a major protein of approximately $240 \mathrm{kDa}$, together with up to eight other components of the Mi-2 complex $(200,150,72,65,63,50$, and $34 \mathrm{kDa})[56,64]$ (Fig. 1). Subsequently, two highly related Mi-2 proteins, $\mathrm{Mi}-2 \alpha$ and $\mathrm{Mi}-2 \beta$ (calculated molecular masses are 220 and $218 \mathrm{kDa}$, respectively), which both contain epitopes that are recognized by anti-Mi-2 antibodies, have been identified as antigens in patients [57, 65]. Although anti-Mi-2 antibodies seem to be more tightly associated with DM, in several studies anti-Mi-2-positive PM and IBM patients have been detected as well $[8,66]$. Therefore, cutaneous characteristics such as Gottron's papules, heliotrope rash, cuticular overgrowth and so-called V-and shawl sign, in combination with autoantibody profiles are considered to be the most reliable diagnostic features for DM [1]. Anti-Mi-2-positive patients tend to respond well to steroid therapy and thus have a relatively good prognostic profile [67].

Recent studies have found elevated Mi-2 expression levels in (regenerating) DM muscle biopsies and in certain tumors associated with autoimmune IIM [51, 68]. Additionally, Kashiwagi et al. [69] described a crucial role of Mi-2 in the development and repair of the basal epidermis, which may support a pathophysiological role for Mi-2 in the development of DM. Moreover, latitudinal differences have been demonstrated to affect the occurrence of DM. 
These studies suggest an important role of environmental factors such as UV-light in the development of DM and anti-Mi-2 formation [70-73]. Anti-Mi-2 antibodies were detected in juvenile DM as well as adult DM, although autoantibody frequency may vary between the different DM subtypes [74-76]. Genetic predispositions in different HLA genes of (non-)Caucasians, but also protein tyrosine phosphatase and pro-inflammatory cytokine genes have been shown to be involved in the development of IIM reviewed by [50]). The HLA-DRB1*0302 and HLADRB1*0701 alleles have been described as risk factors for the generation of anti-Mi-2 antibodies in African-American and Caucasian individuals [50, 77].

\section{How to assay for anti-Mi-2 antibodies}

Several diagnostic assays have been used over the years to detect anti-Mi-2 antibody reactivities in patient sera. To date, home-made tests are still more accurate, however, due to an enhanced reproducibility, sensitivity, and specificity, line-blot techniques will probably be preferred over the more conventional ELISA and IP assays in the future [53].

Signal recognition particle

\section{Function}

Proteins that are involved in intercellular signaling are either being secreted or transported to the plasma membrane. The intracellular translocation of such proteins, from translational site to functional site, is regulated by a specialized secretory pathway. First, newly synthesized proteins have to be directed to the endoplasmic reticulum (ER), which is a signal peptide sequence driven process. This sequence is located at the N-terminus of the protein, and protein translocation can occur post-translationally or co-translationally. Co-translational translocation involves the so-called signal recognition particle (SRP), which is a ribonucleoprotein (RNP) complex that consists of six proteins $(9,14,19,54,68$, and $72 \mathrm{kDa})$ and a RNA molecule of approximately 300 nucleotides, termed 7SL RNA [78]. In the SRP complex two distinct RNP domains can be distinguished (Fig. 8) [79-81]. The S-domain consists of SRP19, SRP54, SRP68, SRP72, and a forked 7SL RNA moiety. It recognizes the signal peptide on the growing peptide chain and targets the complex to the ER membrane. The Alu-domain is formed by SRP9, SRP14 at the opposite end of the 7SL RNA and probably causes a transient translational arrest until the ribosome/nascent chain complex has docked to the ER. The SRP particle has a high affinity for ribosomes containing a protruding signal peptide. After binding, the SRP-ribosome complex binds the SRP receptor (SR) on the ER membrane via GTP- dependent interactions. Subsequently, the ribosome can dock onto the translocon and the binding between signal sequence and SRP complex is broken, allowing translation to resume. Finally, after GTP hydrolysis, SRP and the SR dissociate and the SRP complex is recycled for a following round of translocation reviewed by [82]).

\section{Potentially disease-related PTMs}

Casciola-Rosen et al. [24] described SRP72 as a substrate for $\mathrm{GrB}$ and suggested a pathogenic role for the unique fragments generated in this way.

\section{Antibodies to SRP and their clinical associations}

Reeves et al. [83] were the first to describe the SRP as an autoantigen in IIM patients. Autoantibodies directed to SRP54 are most frequently found, although anti-SRP72, anti-SRP68, and anti-7SL RNA reactivities have been reported as well [84-86]. Patients that generate anti-SRP antibodies (up to $5 \%$ of patients with IIM) appear to form a distinct clinical and histopathological subset within the IIM $[86,87]$. The so-called necrotizing myopathy seen in antiSRP-positive patients, include necrotic and regenerating myofibers. Muscle enzyme elevations as well as lower numbers of infiltrating lymphocytes are found in muscle biopsies compared to PM. In addition, patients with antiSRP antibodies frequently reveal an unusually severe weakness, acute onset, rapid disease progression, and resistance to treatment $[84,87,88]$. These distinct characteristics emphasize that anti-SRP antibodies can be used as a biomarker for a distinct subgroup of IIM patients. Anti-SRP antibodies are rarely detected in juvenile IIM [6].

\section{How to assay for anti-SRP antibodies}

Anti-SRP antibodies, similar to anti-aaRS, anti-Mi-2, and several anti-MAA, can be detected via commercial LIAs. However, Ronnelid et al. [13] found discrepancies in the autoantibody reactivities when commercial LIAs were used at different temperatures. This temperature sensitivity is most pronounced for weakly positive and negative samples, which may result in false- or false-negative diagnoses. This emphasizes the importance of further evaluation and development of commercial LIAs, in order to ensure that specificity and sensitivity are warranted.

\section{CADM-140}

\section{Function}

The innate immune system utilizes a specific group of receptors, the so-called pattern recognition receptors 


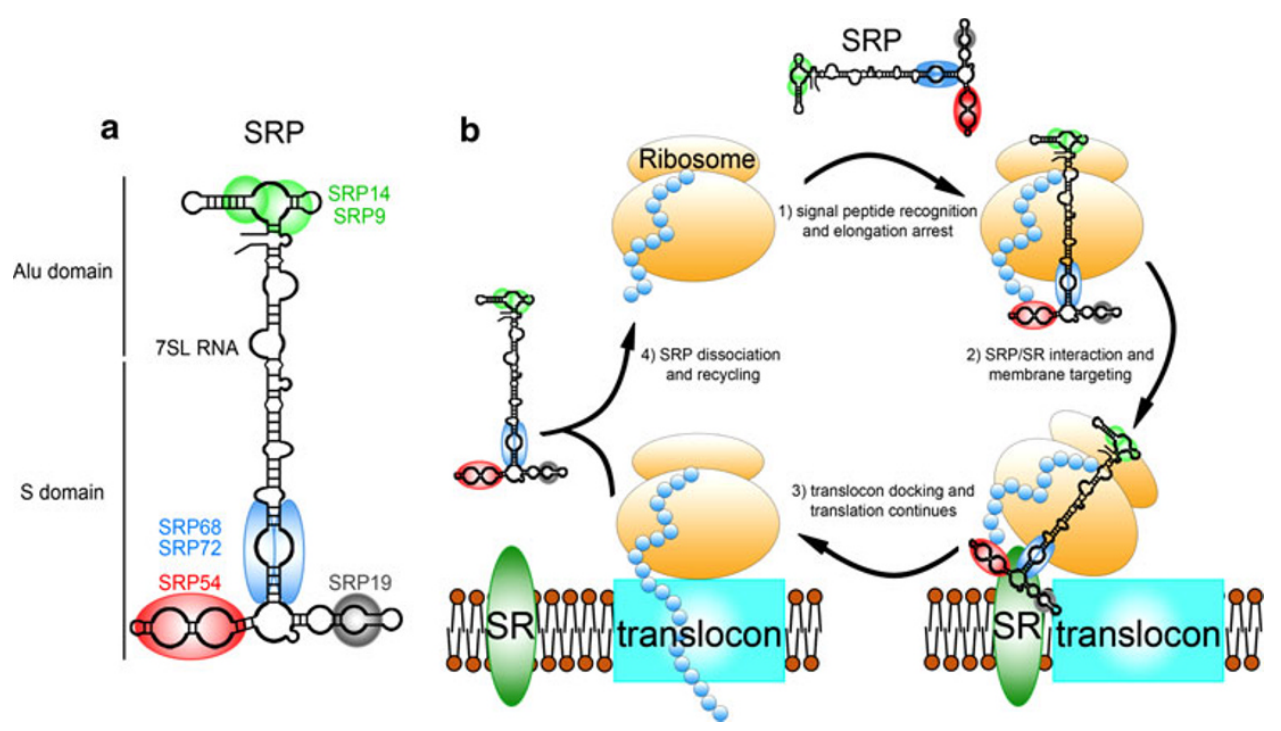

Fig. 8 SRP mediates translocation of nascent, signal peptide-containing proteins: a schematic structure of SRP, $\mathbf{b}$ mechanism of protein translocation mediated by SRP. First, SRP binds to the $\mathrm{N}$-terminal signal peptide of the growing peptide chain which results in elongation arrest (1). Subsequently, the ribosome/SRP complex is

(PRRs), to detect specific pathogenic components [89]. Three major classes of PRRs have been identified, including Toll-like receptors (TLRs), retinoic acidinducible gene I (RIG-I)-like helicases (RLHs) and nucleotide-oligomerization domain (NOD)-like receptors (NLRs). The melanoma differentiation-associated gene 5 (MDA5), or CADM-140 autoantigen, together with RIGI and LGP2 (laboratory of genetics and physiology 2) are members of the RLH helicase family. Both RIG-I and MDA5 contain N-terminal caspase-recruitment domains (CARDs) followed by a $\mathrm{DExD} / \mathrm{H}$ box RNA helicase domain, whereas LGP2 has a similar helicase domain but lacks a CARD domain. LGP2 has been suggested to function as a negative regulator of RIG-I/MDA5 signaling [90-92]. The TLRs and RLHs are able to sense viral RNA and DNA components and downstream signaling results in the activation of cells to produce type I interferons (IFNs) and pro-inflammatory cytokines. These factors stimulate the immune system by activating natural killer (NK) and $\mathrm{T}$ cells, and promote the induction of apoptosis of virus-infected cells and the cellular antiviral response that interferes with cellular and viral processes.

\section{Potentially disease-related PTMs}

Barral et al. [93] describe MDA5/CADM-140 degradation products, both in puromycin-induced apoptotic HeLa cells and poliovirus-infected cells, which is suggested to antagonize the type I IFN-induced anti-viral response. targeted to the SRP receptor (SR) at the ER membrane by specific sequences in the SRP proteins (2). Docking of the complex to the membrane bound translocon releases the signal peptide from the SRP complex and enables translation to continue (3). The SRP dissociates and is recycled for additional translocation events (4)

Disease-associated MDA5/CADM-140 modifications have not been described yet.

\section{Antibodies to CADM-140 and their clinical associations}

The IIM classification criteria enable clinicians to categorize several distinct IIM populations. Some individuals, the so-called amyopathic DM patients, exert typical skin manifestations of DM but little or no evidence of clinical IIM. When patients do not develop clinical symptoms of IIM for at least 2 years after the onset of skin manifestations they will be classified as clinically amyopathic DM (CADM) [94]. Japanese patients with CADM develop a rapidly progressive interstitial lung disease (ILD), which frequently appears to be resistant to treatment and which may lead to early death $[95,96]$. Sato et al. [97] were the first to describe a novel antibody (anti-CADM-140) that immunoprecipitated a $140-\mathrm{kDa}$ protein in $53 \%$ of the CADM patients, whereas no such antibodies were detected in any of the PM or DM patients (Fig. 1). Recently, it was shown that this $140-\mathrm{kDa}$ protein is identical to MDA5 [98]. It is intriguing that anti-CADM-140 antibodies are only reported to occur in Japanese patients so far. Nakashima et al. [99] confirmed the anti-CADM-140 antibody to be specific for CADM, although a few positive patients showed symptoms of IIM (DM according to criteria). A recent report from Hoshino et al. [100], suggested that antiCADM140/MDA5 autoantibodies could be used as a novel serological marker to distinguish between different DM subsets and associated clinical complications. 


\section{How to assay for anti-CADM-140 antibodies}

No commercial assay is available yet for the detection of the anti-CADM-140 antibody. Sato et al. [97] used immunoprecipitation, immunoblotting, and indirect immunofluorescence techniques to detect this specificity. In addition, an ELISA, containing the recombinant CADM140 protein as antigen, was used to test for anti-CADM140 antibodies with a fairly high sensitivity and specificity [98]. The recombinant CADM-140 antigen might be suitable for the development of a commercial test.

\section{p155/140}

\section{Function}

The Tif $1-\gamma$, or $\mathrm{p} 155 / 140$ protein has been characterized as a member of the transcriptional intermediary factor 1 (Tif1) gene family [101-103]. Similar to the other Tif1 members, Tif1- $\alpha$ and Tif1- $\beta$, Tif1- $\gamma$ contains several specific protein domains, including a RING finger, B-boxes, a coiled-coil domain, a PHD/TTC domain, and a bromodomain involved in protein-protein interactions. Several possible functions of the Tif $1-\gamma$ protein have been described, including regulation of transcription and maintenance of tissue homeostasis $[104,105]$.

While the antigenic p155 protein (one of the two antigenic proteins) has been identified as Tif $1-\gamma$, the identity of the p140 protein remains elusive [103].

\section{Potentially disease-related PTMs}

No modifications have been associated with disease.

\section{Antibodies to p155/140 and their clinical associations}

Several studies indicated that anti-p155/140 antibodies appear to be associated with adult and juvenile DM (JDM) patients [106]. Up to $23 \%$ of DM patients seem to contain autoantibodies reactive with a $155 / 140-\mathrm{kDa}$ protein doublet (Fig. 1). The positive adult DM patients often have more severe cutaneous involvement and an increased risk for malignancies (particularly adenocarcinomas) [106-109]. Follow-up studies confirmed the cancer-associated DM (C-ADM) subset specificity of the anti-p155/140 antibody [100]. The anti-p155/140 antibody is detected in JDM sera with a similar frequency as in adult DM, although the association with malignancy in JDM was not observed [110].

\section{How to assay for anti-p155/140 antibodies}

Anti-p155/140 was first identified using an immunoprecipitation procedure with C-ADM patient sera and radiolabelled K562 cell extracts and immunoblotting [106]. Recently, the immunoprecipitation of biotinylated recombinant Tif1- $\gamma$ was used to evaluate the clinical features associated with anti-p155/140 in DM patients [100]. The availability of such recombinant proteins might encourage the development of a commercial diagnostic test.

Small ubiquitin-like modifier activating enzyme (SAE)

\section{Function}

Many enzymes are involved in post-translational protein modifications, and thereby regulate protein activity, subcellular localization, stability, and protein-protein interactions. These protein modifications can be a response to environmental triggers or depend on the cellular state. The SUMO protein family is structurally related to ubiquitin, and, like ubiquitin, can be post-translationally conjugated to other proteins by a similar mechanism. SUMO needs to be activated before post-translational conjugation can occur. This process is regulated by the SUMO-activating enzyme (E1) and involves the small ubiquitin-like modifier activating enzyme (SAE), which consists of a heterodimer of SAE1 and SAE2. Sumoylation is found to be involved in a variety of processes such as nuclear protein transport, DNA replication and repair, and cell division [111]. In addition, the number of substrates is increasing and emphasizes the diverse roles of SUMO modification in many cellular processes [112]. Although several SUMO family members have been shown to play role in the sumoylation of proteins, information about the consequences of sumoylation on the functions of these proteins is rather scarce.

\section{Potentially disease-related PTMs}

No disease-associated modifications have been documented.

\section{Antibodies to SAE and their clinical associations}

Betteridge et al. [113] reported a novel autoantibody in adult DM patients that immunoprecipitated two uncharacterized bands at 40 and $90 \mathrm{kDa}$. Further proteomic analysis identified the autoantigenic targets as small ubiquitin-like modifier activating enzyme (SAE) subunits. A large scale autoantibody screening by IP identified anti-SAE antibodies in $8.4 \%$ of DM patients. These results suggest that anti-SAE may identify a new serological IIM subset that present initially CADM and progress to develop IIM with a high frequency of systemic features except interstitial pneumonia. 


\section{How to assay for anti-SAE antibodies}

Anti-SAE antibodies can be detected by immunoprecipitation and show a diffuse, coarse, speckled, nucleolarsparing pattern in indirect immunofluorescence analysis $[113,114]$.

p140

\section{Function}

The NXP-2 protein is a recently identified nuclear matrix associated protein. Ectopically expressed NXP-2 mutants and structure prediction programs allowed the identification of several functional domains for NXP-2, including RNA-binding, nuclear matrix-binding, and coiled-coil domains [115]. Northern blot analysis showed NXP-2 to be expressed in specific tissues and at different levels. Moreover, RNA-binding and nuclear-binding capacities of NXP-2 suggest a similar role in the control of posttranscriptional processes as are described for other nuclear matrix proteins that contain similar domains [116]. Rosendorff and co-workers [117] reported a transcriptional repressor activity for the NXP-2 in vitro, which may be mediated by SUMO modification. These results suggest that NXP-2 may be involved in tissuespecific RNA metabolism and maintenance of nuclear structure rather than being a constitutive factor in nuclear functions.

\section{Potentially disease-related PTMs}

NXP-2 was recently described to be a candidate substrate for SUMO modification, which might result in the downregulation of transcription [112, 117]. However, whether this results in the initiation of pathogenic mechanisms leading to immunological dysregulation is not known yet.

\section{Antibodies to p140 and their clinical associations}

Oddis et al. [118] described autoantibodies directed against a 140-kDa target (anti-MJ) in a cohort of juvenile IIM patients. Later, Gunawardena et al. [119] identified antibodies to a $140-\mathrm{kDa}$ protein in $23 \%$ of juvenile IIM sera that form a distinct JDM subset. The p140 autoantigen targeted by these antibodies is different from the p155/140 antigen described above. Immunodepletion experiments with reference anti-p140-positive sera and anti-NXP-2 monoclonal antibodies suggested that the p140 protein is identical to the MJ autoantigen. Recent studies of Targoff's group [120] characterized the p140/MJ antigen and described the 140 protein as the nuclear matrix protein (NXP-2).
The presence of this anti-p140 antibody is associated with calcinosis, which defines a different clinical phenotypic JDM subset.

\section{How to assay for anti-p140 antibodies}

Radiolabelled immunoprecipitation assays have been used to identify the presence of this antibody activity [119].

Novel MSAs

Christopher-Stine et al. [121] recently described a novel autoantibody in a subset of individuals suffering from necrotizing myopathy, which previously were considered to be autoantibody negative. They studied 255 patients with myopathies and found 38 muscle biopsies with necrotizing myopathies. Twenty-six patients were diagnosed as autoantibody negative, whereas in the remaining 12 sera antiSRP or anti-aaRS activities were detected. Screening of the 26 negative sera for putative novel autoantibody reactivities by immunoprecipitation resulted in the detection of two antigenic proteins with molecular weights of approximately 200 and $100 \mathrm{kDa}$ in $62 \%$ of these patients. The evaluation of clinical data suggested that patients with anti200/100 antibodies form a separate group of necrotizing myopathies that are associated with the exposure to statin medication and are responsive to immunosuppression. Further characterization of the anti-200/100 target might contribute to the understanding how this particular subset can develop.

\section{Concluding remarks and perspectives}

The characterization of MSA and the development of methods to detect these autoantibodies in patient sera for diagnostic purposes represent an active field of research. A series of novel MSA have been identified during the last decade and new technologies have been developed for their identification and detection, especially using multiplex assays. The application of multiplex assays will not only facilitate the simultaneous detection of multiple autoantibody reactivities, MSA as well as MAA, but may also allow the identification of autoantibody profiles that might have additional diagnostic or prognostic value.

Although the prevalence of MSAs in IIM patients is generally relatively low $(<20 \%)$, for a number of them clinical associations have indeed been identified. Several reports indicate that MSAs are able to discriminate between distinct disease entities and/or can be correlated to disease severity, which suggests that MSAs might help define IIM subtypes and predict disease progression, and/or treatment. The number of MSA is steadily growing and the 
diverse functions and subcellular localizations of the associated autoantigenic targets suggest selective mechanisms in the development of these autoantibodies. Whether autoantibodies directly contribute to the development and/ or progression of IIM, however, remains elusive. All MSA that have been characterized up to now are associated with $\mathrm{PM}$ and/or DM. An intriguing question is whether MSA are also produced by patients with the third major type of IIM, IBM.

The detection of novel autoantibody targets in the different immune-mediated myopathies emphasizes the complexity of the mechanisms that define the development of these autoimmune diseases. Further studies that elucidate structure and function of autoantigenic targets will be essential in understanding the underlying pathological mechanisms in IIM.

Acknowledgments We would like to thank B. van Engelen (UMCN, The Netherlands) for critically reading the manuscript as well as EUROIMMUN who generously provided line-blots free-ofcharge. This work was financially supported by the European Union Sixth Framework Programme (project Autocure; LSH-018661).

Conflict of interest None.

\section{References}

1. Mammen AL (2010) Dermatomyositis and polymyositis: clinical presentation, autoantibodies, and pathogenesis. Ann NY Acad Sci 1184:134-153

2. Walker UA (2008) Imaging tools for the clinical assessment of idiopathic inflammatory myositis. Curr Opin Rheumatol 20:656-661

3. Tozzoli R (2007) Recent advances in diagnostic technologies and their impact in autoimmune diseases. Autoimmun Rev 6:334-340

4. Sharp V, Utz PJ (2007) Technology insight: can autoantibody profiling improve clinical practice? Nat Clin Pract Rheumatol 3:96-103

5. Betteridge Z, Gunawardena H, North J et al (2007) Anti-synthetase syndrome: a new autoantibody to phenylalanyl transfer RNA synthetase (anti-Zo) associated with polymyositis and interstitial pneumonia. Rheumatology (Oxford) 46:1005-1008

6. Gunawardena H, Betteridge ZE, McHugh NJ (2009) Myositisspecific autoantibodies: their clinical and pathogenic significance in disease expression. Rheumatology (Oxford) 48:607-612

7. Tan EM, Smolen JS, McDougal JS et al (1999) A critical evaluation of enzyme immunoassays for detection of antinuclear autoantibodies of defined specificities. I. Precision, sensitivity, and specificity. Arthritis Rheum 42:455-464

8. Brouwer R, Hengstman GJ, Vree EW et al (2001) Autoantibody profiles in the sera of European patients with myositis. Ann Rheum Dis 60:116-123

9. Robinson WH, DiGennaro C, Hueber W et al (2002) Autoantigen microarrays for multiplex characterization of autoantibody responses. Nat Med 8:295-301

10. Bizzaro N, Bonelli F, Tonutti E et al (2001) New coupledparticle light-scattering assay for detection of Ro/SSA (52 and
60 kilodaltons) and La/SSB autoantibodies in connective tissue diseases. Clin Diagn Lab Immunol 8:922-925

11. Fulton RJ, McDade RL, Smith PL et al (1997) Advanced multiplexed analysis with the FlowMetrix system. Clin Chem 43:1749-1756

12. Fritzler MJ (2006) Advances and applications of multiplexed diagnostic technologies in autoimmune diseases. Lupus $15: 422-427$

13. Ronnelid J, Barbasso HS, Storfors H et al (2009) Use of a commercial line blot assay as a screening test for autoantibodies in inflammatory myopathies. Autoimmun Rev 9:58-61

14. Ghirardello A, Bendo R, Rampudda ME et al (2009) Commercial blot assays in the diagnosis of systemic rheumatic diseases. Autoimmun Rev 8:645-649

15. Ting SM, Bogner P, Dignam JD (1992) Isolation of prolyl-tRNA synthetase as a free form and as a form associated with glutamyl-tRNA synthetase. J Biol Chem 267:17701-17709

16. Quevillon S, Robinson JC, Berthonneau E et al (1999) Macromolecular assemblage of aminoacyl-tRNA synthetases: identification of protein-protein interactions and characterization of a core protein. J Mol Biol 285:183-195

17. Hausmann CD, Ibba M (2008) Aminoacyl-tRNA synthetase complexes: molecular multitasking revealed. FEMS Microbiol Rev 32:705-721

18. Guo M, Yang XL, Schimmel P (2010) New functions of aminoacyl-tRNA synthetases beyond translation. Nat Rev Mol Cell Biol 11:668-674

19. Cusack S (1997) Aminoacyl-tRNA synthetases. Curr Opin Struct Biol 7:881-889

20. Kyriacou SV, Deutscher MP (2008) An important role for the multienzyme aminoacyl-tRNA synthetase complex in mammalian translation and cell growth. Mol Cell 29:419-427

21. Ray PS, Arif A, Fox PL (2007) Macromolecular complexes as depots for releasable regulatory proteins. Trends Biochem Sci 32:158-164

22. Heusel JW, Wesselschmidt RL, Shresta S et al (1994) Cytotoxic lymphocytes require granzyme B for the rapid induction of DNA fragmentation and apoptosis in allogeneic target cells. Cell 76:977-987

23. Shresta S, MacIvor DM, Heusel JW et al (1995) Natural killer and lymphokine-activated killer cells require granzyme B for the rapid induction of apoptosis in susceptible target cells. Proc Natl Acad Sci USA 92:5679-5683

24. Casciola-Rosen L, Andrade F, Ulanet D et al (1999) Cleavage by granzyme B is strongly predictive of autoantigen status: implications for initiation of autoimmunity. J Exp Med 190:815-826

25. Howard OM, Dong HF, Yang D et al (2002) Histidyl-tRNA synthetase and asparaginyl-tRNA synthetase, autoantigens in myositis, activate chemokine receptors on $\mathrm{T}$ lymphocytes and immature dendritic cells. J Exp Med 196:781-791

26. Oppenheim JJ, Dong HF, Plotz P et al (2005) Autoantigens act as tissue-specific chemoattractants. J Leukoc Biol 77:854-861

27. Levine SM, Raben N, Xie D et al (2007) Novel conformation of histidyl-transfer RNA synthetase in the lung: the target tissue in Jo-1 autoantibody-associated myositis. Arthritis Rheum 56:2729-2739

28. Ramirez-Sandoval R, Sanchez-Rodriguez SH, Herrera-van OD et al (2003) Antinuclear antibodies recognize cellular autoantigens driven by apoptosis. Joint Bone Spine 70:187-194

29. Wakasugi K, Schimmel P (1999) Highly differentiated motifs responsible for two cytokine activities of a split human tRNA synthetase. J Biol Chem 274:23155-23159

30. Wakasugi K, Slike BM, Hood J et al (2002) A human aminoacyl-tRNA synthetase as a regulator of angiogenesis. Proc Natl Acad Sci USA 99:173-177 
31. Henrotin YE, Bruckner P, Pujol JP (2003) The role of reactive oxygen species in homeostasis and degradation of cartilage. Osteoarthr Cartil 11:747-755

32. Sakurai H, Kohsaka H, Liu MF et al (1995) Nitric oxide production and inducible nitric oxide synthase expression in inflammatory arthritides. J Clin Invest 96:2357-2363

33. Wedderburn LR, McHugh NJ, Chinoy H et al (2007) HLA class II haplotype and autoantibody associations in children with juvenile dermatomyositis and juvenile dermatomyositis-scleroderma overlap. Rheumatology (Oxford) 46:1786-1791

34. Brouwer R, Vree EW, Jongen PH et al (1998) Frequent occurrence of anti-tRNA(His) autoantibodies that recognize a conformational epitope in sera of patients with myositis. Arthritis Rheum 41:1428-1437

35. Bunn CC, Bernstein RM, Mathews MB (1986) Autoantibodies against alanyl-tRNA synthetase and tRNAAla coexist and are associated with myositis. J Exp Med 163:1281-1291

36. Gelpi C, Kanterewicz E, Gratacos J et al (1996) Coexistence of two antisynthetases in a patient with the antisynthetase syndrome. Arthritis Rheum 39:692-697

37. Nishikai M, Reichlin M (1980) Heterogeneity of precipitating antibodies in polymyositis and dermatomyositis. Characterization of the Jo-1 antibody system. Arthritis Rheum 23:881-888

38. Mimori T, Imura Y, Nakashima R et al (2007) Autoantibodies in idiopathic inflammatory myopathy: an update on clinical and pathophysiological significance. Curr Opin Rheumatol 19:523-529

39. Hengstman GJ, van Engelen BG, Badrising UA et al (1998) Presence of the anti-Jo-1 autoantibody excludes inclusion body myositis. Ann Neurol 44:423

40. Stone KB, Oddis CV, Fertig N et al (2007) Anti-Jo-1 antibody levels correlate with disease activity in idiopathic inflammatory myopathy. Arthritis Rheum 56:3125-3131

41. Raben N, Nichols R, Dohlman J et al (1994) A motif in human histidyl-tRNA synthetase which is shared among several aminoacyl-tRNA synthetases is a coiled-coil that is essential for enzymatic activity and contains the major autoantigenic epitope. J Biol Chem 269:24277-24283

42. Dohlman JG, Lupas A, Carson M (1993) Long charge-rich alpha-helices in systemic autoantigens. Biochem Biophys Res Commun 195:686-696

43. Martin A, Shulman MJ, Tsui FW (1995) Epitope studies indicate that histidyl-tRNA synthetase is a stimulating antigen in idiopathic myositis. FASEB J 9:1226-1233

44. Miller FW, Waite KA, Biswas T et al (1990) The role of an autoantigen, histidyl-tRNA synthetase, in the induction and maintenance of autoimmunity. Proc Natl Acad Sci USA 87:9933-9937

45. Katsumata Y, Ridgway WM, Oriss T et al (2007) Species-specific immune responses generated by histidyl-tRNA synthetase immunization are associated with muscle and lung inflammation. J Autoimmun 29:174-186

46. Hengstman GJ, van Engelen BG, van Venrooij WJ (2004) Myositis specific autoantibodies: changing insights in pathophysiology and clinical associations. Curr Opin Rheumatol 16:692-699

47. Kalluri M, Sahn SA, Oddis CV et al (2009) Clinical profile of anti-PL-12 autoantibody. Cohort study and review of the literature. Chest 135:1550-1556

48. Marguerie C, Bunn CC, Beynon HL et al (1990) Polymyositis, pulmonary fibrosis and autoantibodies to aminoacyl-tRNA synthetase enzymes. Q J Med 77:1019-1038

49. Marie I, Hachulla E, Cherin P et al (2002) Interstitial lung disease in polymyositis and dermatomyositis. Arthritis Rheum 47:614-622
50. Chinoy H, Lamb JA, Ollier WE et al (2009) An update on the immunogenetics of idiopathic inflammatory myopathies: major histocompatibility complex and beyond. Curr Opin Rheumatol 21:588-593

51. Casciola-Rosen L, Nagaraju K, Plotz P et al (2005) Enhanced autoantigen expression in regenerating muscle cells in idiopathic inflammatory myopathy. J Exp Med 201:591-601

52. Zampieri S, Biral D, Adami $\mathrm{N}$ et al (2008) Expression of myositis specific autoantigens during post-natal myogenesis. Neurol Res 30:145-148

53. Ghirardello A, Rampudda M, Ekholm L et al (2010) Diagnostic performance and validation of autoantibody testing in myositis by a commercial line blot assay. Rheumatology (Oxford) 49:2370-2374

54. Becker PB, Horz W (2002) ATP-dependent nucleosome remodeling. Annu Rev Biochem 71:247-273

55. Ehrenhofer-Murray AE (2004) Chromatin dynamics at DNA replication, transcription and repair. Eur $\mathrm{J}$ Biochem 271:2335-2349

56. Ge Q, Nilasena DS, O’Brien CA et al (1995) Molecular analysis of a major antigenic region of the $240-\mathrm{kD}$ protein of $\mathrm{Mi}-2$ autoantigen. J Clin Invest 96:1730-1737

57. Seelig HP, Moosbrugger I, Ehrfeld H et al (1995) The major dermatomyositis-specific Mi-2 autoantigen is a presumed helicase involved in transcriptional activation. Arthritis Rheum 38:1389-1399

58. Ramirez J, Hagman J (2009) The Mi-2/NuRD complex: a critical epigenetic regulator of hematopoietic development, differentiation and cancer. Epigenetics 4:532-536

59. Bowen NJ, Fujita N, Kajita M et al (2004) Mi-2/NuRD: multiple complexes for many purposes. Biochim Biophys Acta 1677:52-57

60. Denslow SA, Wade PA (2007) The human Mi-2/NuRD complex and gene regulation. Oncogene 26:5433-5438

61. Gong Z, Brackertz M, Renkawitz R (2006) SUMO modification enhances p66-mediated transcriptional repression of the Mi-2/ NuRD complex. Mol Cell Biol 26:4519-4528

62. Reichlin M, Mattioli M (1976) Description of a serological reaction characteristic of polymyositis. Clin Immunol Immunopathol 5:12-20

63. Targoff IN, Reichlin M (1985) The association between Mi-2 antibodies and dermatomyositis. Arthritis Rheum 28:796-803

64. Nilasena DS, Trieu EP, Targoff IN (1995) Analysis of the Mi-2 autoantigen of dermatomyositis. Arthritis Rheum 38:123-128

65. Seelig HP, Renz M, Targoff IN et al (1996) Two forms of the major antigenic protein of the dermatomyositis-specific Mi-2 autoantigen. Arthritis Rheum 39:1769-1771

66. Hengstman GJ, Vree Egberts WT, Seelig HP et al (2006) Clinical characteristics of patients with myositis and autoantibodies to different fragments of the Mi-2 beta antigen. Ann Rheum Dis 65:242-245

67. Love LA, Leff RL, Fraser DD et al (1991) A new approach to the classification of idiopathic inflammatory myopathy: myositis-specific autoantibodies define useful homogeneous patient groups. Medicine (Baltimore) 70:360-374

68. Mammen AL, Casciola-Rosen LA, Hall JC et al (2009) Expression of the dermatomyositis autoantigen Mi-2 in regenerating muscle. Arthritis Rheum 60:3784-3793

69. Kashiwagi M, Morgan BA, Georgopoulos K (2007) The chromatin remodeler Mi-2beta is required for establishment of the basal epidermis and normal differentiation of its progeny. Development 134:1571-1582

70. Hengstman GJ, van Venrooij WJ, Vencovsky J et al (2000) The relative prevalence of dermatomyositis and polymyositis in Europe exhibits a latitudinal gradient. Ann Rheum Dis 59:141-142 
71. Okada S, Weatherhead E, Targoff IN et al (2003) Global surface ultraviolet radiation intensity may modulate the clinical and immunologic expression of autoimmune muscle disease. Arthritis Rheum 48:2285-2293

72. Love LA, Weinberg CR, McConnaughey DR et al (2009) Ultraviolet radiation intensity predicts the relative distribution of dermatomyositis and anti-Mi-2 autoantibodies in women. Arthritis Rheum 60:2499-2504

73. Burd CJ, Kinyamu HK, Miller FW et al (2008) UV radiation regulates Mi-2 through protein translation and stability. J Biol Chem 283:34976-34982

74. Rider LG, Miller FW, Targoff IN et al (1994) A broadened spectrum of juvenile myositis. Myositis-specific autoantibodies in children. Arthritis Rheum 37:1534-1538

75. Feldman BM, Reichlin M, Laxer RM et al (1996) Clinical significance of specific autoantibodies in juvenile dermatomyositis. J Rheumatol 23:1794-1797

76. Shamim EA, Rider LG, Pandey JP et al (2002) Differences in idiopathic inflammatory myopathy phenotypes and genotypes between Mesoamerican Mestizos and North American Caucasians: ethnogeographic influences in the genetics and clinical expression of myositis. Arthritis Rheum 46:1885-1893

77. O'Hanlon TP, Rider LG, Mamyrova G et al (2006) HLA polymorphisms in African Americans with idiopathic inflammatory myopathy: allelic profiles distinguish patients with different clinical phenotypes and myositis autoantibodies. Arthritis Rheum 54:3670-3681

78. Walter P, Blobel G (1980) Purification of a membrane-associated protein complex required for protein translocation across the endoplasmic reticulum. Proc Natl Acad Sci USA 77:7112-7116

79. Gundelfinger ED, Krause E, Melli M et al (1983) The organization of the 7SL RNA in the signal recognition particle. Nucleic Acids Res 11:7363-7374

80. Walter P, Johnson AE (1994) Signal sequence recognition and protein targeting to the endoplasmic reticulum membrane. Annu Rev Cell Biol 10:87-119

81. Siegel V, Walter P (1988) Functional dissection of the signal recognition particle. Trends Biochem Sci 13:314-316

82. Egea PF, Stroud RM, Walter P (2005) Targeting proteins to membranes: structure of the signal recognition particle. Curr Opin Struct Biol 15:213-220

83. Reeves WH, Nigam SK, Blobel G (1986) Human autoantibodies reactive with the signal-recognition particle. Proc Natl Acad Sci USA 83:9507-9511

84. Targoff IN, Johnson AE, Miller FW (1990) Antibody to signal recognition particle in polymyositis. Arthritis Rheum $33: 1361-1370$

85. Okada N, Mimori T, Mukai R et al (1987) Characterization of human autoantibodies that selectively precipitate the 7SL RNA component of the signal recognition particle. J Immunol 138:3219-3223

86. Satoh T, Okano T, Matsui T et al (2005) Novel autoantibodies against 7SL RNA in patients with polymyositis/dermatomyositis. J Rheumatol 32:1727-1733

87. Hengstman GJ, ter Laak HJ, Vree Egberts WT et al (2006) Antisignal recognition particle autoantibodies: marker of a necrotising myopathy. Ann Rheum Dis 65:1635-1638

88. Miller T, Al-Lozi MT, Lopate G et al (2002) Myopathy with antibodies to the signal recognition particle: clinical and pathological features. J Neurol Neurosurg Psychiatry 73:420-428

89. Meylan E, Tschopp J, Karin M (2006) Intracellular pattern recognition receptors in the host response. Nature 442:39-44

90. Yoneyama M, Kikuchi M, Matsumoto K et al (2005) Shared and unique functions of the DExD/H-box helicases RIG-I, MDA5, and LGP2 in antiviral innate immunity. $\mathbf{J}$ Immunol $175: 2851-2858$

91. Rothenfusser S, Goutagny N, DiPerna G et al (2005) The RNA helicase Lgp2 inhibits TLR-independent sensing of viral replication by retinoic acid-inducible gene-I. J Immunol 175:5260-5268

92. Saito T, Hirai R, Loo YM et al (2007) Regulation of innate antiviral defenses through a shared repressor domain in RIG-I and LGP2. Proc Natl Acad Sci USA 104:582-587

93. Barral PM, Morrison JM, Drahos J et al (2007) MDA-5 is cleaved in poliovirus-infected cells. J Virol 81:3677-3684

94. Sontheimer RD (2002) Dermatomyositis: an overview of recent progress with emphasis on dermatologic aspects. Dermatol Clin 20:387-408

95. Tokiyama K, Tagawa H, Yokota E et al (1990) Two cases of amyopathic dermatomyositis with fatal rapidly progressive interstitial pneumonitis. Ryumachi 30:204-209

96. Fujikawa K, Kawakami A, Kaji K et al (2009) Association of distinct clinical subsets with myositis-specific autoantibodies towards anti-155/140-kDa polypeptides, anti-140-kDa polypeptides, and anti-aminoacyl tRNA synthetases in Japanese patients with dermatomyositis: a single-centre, cross-sectional study. Scand J Rheumatol 38:263-267

97. Sato S, Hirakata M, Kuwana M et al (2005) Autoantibodies to a 140-kd polypeptide, CADM-140, in Japanese patients with clinically amyopathic dermatomyositis. Arthritis Rheum 52:1571-1576

98. Sato S, Hoshino K, Satoh T et al (2009) RNA helicase encoded by melanoma differentiation-associated gene 5 is a major autoantigen in patients with clinically amyopathic dermatomyositis: association with rapidly progressive interstitial lung disease. Arthritis Rheum 60:2193-2200

99. Nakashima R, Imura Y, Kobayashi S et al (2010) The RIG-I-like receptor IFIH1/MDA5 is a dermatomyositis-specific autoantigen identified by the anti-CADM-140 antibody. Rheumatology (Oxford) 49:433-440

100. Hoshino K, Muro Y, Sugiura K et al (2010) Anti-MDA5 and anti-TIF1-gamma antibodies have clinical significance for patients with dermatomyositis. Rheumatology (Oxford) 49:1726-1733

101. Venturini L, You J, Stadler M et al (1999) TIF1 gamma, a novel member of the transcriptional intermediary factor 1 family. Oncogene 18:1209-1217

102. Reymond A, Meroni G, Fantozzi A et al (2001) The tripartite motif family identifies cell compartments. EMBO J 20:2140-2151

103. Targoff IN, Trieu EP, Levy-Neto M et al (2006) Autoantibodies to transcriptional intermediary factor-1 gamma (TIF-1g) in dermatomyositis (abstract). Arthritis Rheum 54:S518

104. He W, Dorn DC, Erdjument-Bromage H et al (2006) Hematopoiesis controlled by distinct TIF1gamma and Smad4 branches of the TGFbeta pathway. Cell 125:929-941

105. Bai X, Kim J, Yang Z et al (2010) TIF1gamma controls erythroid cell fate by regulating transcription elongation. Cell 142:133-143

106. Targoff IN, Mamyrova G, Trieu EP et al (2006) A novel autoantibody to a $155-\mathrm{kd}$ protein is associated with dermatomyositis. Arthritis Rheum 54:3682-3689

107. Kaji K, Fujimoto M, Hasegawa M et al (2007) Identification of a novel autoantibody reactive with 155 and $140 \mathrm{kDa}$ nuclear proteins in patients with dermatomyositis: an association with malignancy. Rheumatology (Oxford) 46:25-28

108. Chinoy H, Fertig N, Oddis CV et al (2007) The diagnostic utility of myositis autoantibody testing for predicting the risk of cancer-associated myositis. Ann Rheum Dis 66:1345-1349 
109. Trallero-Araguas E, Labrador-Horrillo M, Selva-O'Callaghan A et al (2010) Cancer-associated myositis and anti-p155 autoantibody in a series of 85 patients with idiopathic inflammatory myopathy. Medicine (Baltimore) 89:47-52

110. Gunawardena H, Wedderburn LR, North J et al (2008) Clinical associations of autoantibodies to a p155/140 kDa doublet protein in juvenile dermatomyositis. Rheumatology (Oxford) 47:324-328

111. Dohmen RJ (2004) SUMO protein modification. Biochim Biophys Acta 1695:113-131

112. Zhao Y, Kwon SW, Anselmo A et al (2004) Broad spectrum identification of cellular small ubiquitin-related modifier (SUMO) substrate proteins. J Biol Chem 279:20999-21002

113. Betteridge Z, Gunawardena $H$, North J et al (2007) Identification of a novel autoantibody directed against small ubiquitin-like modifier activating enzyme in dermatomyositis. Arthritis Rheum 56:3132-3137

114. Betteridge ZE, Gunawardena H, Chinoy H et al (2009) Clinical and human leucocyte antigen class II haplotype associations of autoantibodies to small ubiquitin-like modifier enzyme, a dermatomyositis-specific autoantigen target, in UK Caucasian adult-onset myositis. Ann Rheum Dis 68:1621-1625

115. Kimura Y, Sakai F, Nakano O et al (2002) The newly identified human nuclear protein NXP-2 possesses three distinct domains, the nuclear matrix-binding, RNA-binding, and coiled-coil domains. J Biol Chem 277:20611-20617

116. Swanson MS, Dreyfuss G (1988) Classification and purification of proteins of heterogeneous nuclear ribonucleoprotein particles by RNA-binding specificities. Mol Cell Biol 8:2237-2241

117. Rosendorff A, Sakakibara S, Lu S et al (2006) NXP-2 association with SUMO-2 depends on lysines required for transcriptional repression. Proc Natl Acad Sci USA 103:5308-5313

118. Oddis CV, Fertig N, Goel A et al (1997) Clinical and serological characterization of the anti-MJ antibody in childhood myositis [abstract]. Arthritis Rheum 40:S139

119. Gunawardena H, Wedderburn LR, Chinoy H et al (2009) Autoantibodies to a $140-\mathrm{kd}$ protein in juvenile dermatomyositis are associated with calcinosis. Arthritis Rheum 60:1807-1814

120. Targoff IN, Trieu EP, Levy-Neto M et al (2007) Sera with autoantibodies to the MJ antigen react with NXP2. Arthritis Rheum 56:S787

121. Christopher-Stine L, Casciola-Rosen LA, Hong G et al (2010) A novel autoantibody recognizing $200-\mathrm{kd}$ and $100-\mathrm{kd}$ proteins is associated with an immune-mediated necrotizing myopathy. Arthritis Rheum 62:2757-2766 